\title{
Nedaplatin: A Radiosensitizing Agent for Patients with Cervical Cancer
}

\author{
Seiji Mabuchi and Tadashi Kimura \\ Department of Obstetrics and Gynecology, Osaka University Graduate School of Medicine, 2-2 Yamadaoka, Suita, \\ Osaka 565-0871, Japan \\ Correspondence should be addressed to Seiji Mabuchi, smabuchi@gyne.med.osaka-u.ac.jp
}

Received 17 June 2010; Accepted 27 August 2010

Academic Editor: Athanassios Tsakris

Copyright (๑) 2011 S. Mabuchi and T. Kimura. This is an open access article distributed under the Creative Commons Attribution License, which permits unrestricted use, distribution, and reproduction in any medium, provided the original work is properly cited.

\begin{abstract}
Despite the recent advances in the management of cervical cancer using cisplatin-based concurrent chemoradiotherapy, substantial treatment failure still occurs, especially in advanced-stage patients and early-stage cervical cancer patients with high-risk prognostic factors. Therefore, efforts to further improve the survival and quality of life of these patients are necessary. Nedaplatin (cis-diammine-glycoplatinum), a derivative of cisplatin, was developed with the aim of producing a treatment with a similar effectiveness to cisplatin but decreased renal and gastrointestinal toxicities. Based on the promising results of preclinical studies, the clinical efficacy of nedaplatin as a radiosensitizing agent was evaluated in patients with cervical cancer. Retrospective analysis of nedaplatin-based concurrent chemoradiotherapy (CCRT) against cervical cancer suggested that nedaplatin-based CCRT can be considered as an alternative to cisplatin-based CCRT in both early-stage and advanced-stage cervical cancer patients. However, due to the lack of a randomized controlled study, nedaplatin-based CCRT has not been convincingly proven to be clinically effective in patients with cervical cancer. Further investigations in randomized controlled trials are therefore needed.
\end{abstract}

\section{Introduction}

Nedaplatin (cis-diammine-glycoplatinum), a derivative of cisplatin, was developed in 1983 by Shionogi Pharmaceutical Company in Japan with the aim of producing a treatment with a similar effectiveness to cisplatin but decreased renal and gastrointestinal toxicities [1]. As shown in Figure 1, nedaplatin has a novel chemical structure involving a fivemembered ring structure in which glycolate is bound to the platinum ion as a bidentate ligand.

In a preclinical evaluation of cervical cancer, nedaplatin demonstrated similar antitumor activity to cisplatin $[2,3]$. Its lower incidence of nephrotoxicity in comparison to cisplatin has been demonstrated to be associated with differences in the kidney distribution of these drugs. When the two agents were administered at the same dose, the accumulation of nedaplatin in the rat kidney was approximately $40 \%$ of that of cisplatin, which explains why nedaplatin is associated with less nephrotoxicity than cisplatin $[4,5]$.
Clinically, previous phase II studies conducted in Japan suggested that nedaplatin has a particularly favorable clinical efficacy towards squamous cell carcinoma (SCC) of the lung, head and neck, esophagus, and uterine cervix [69]. According to a clinical study of nedaplatin in nonsmall cell lung cancer patients, the response rate in patients with SCC histology was $57.1 \%$, which is significantly higher than $5.5 \%$ observed in patients with nonSCC histology [9]. In the area of uterine cervical cancer, in a phase II clinical trial, nedaplatin demonstrated a response rate of $46 \%$ in patients with recurrent cervical cancer, which was slightly superior to that obtained with cisplatin (39\%) [8]. Moreover, since nedaplatin does not require hydration, nedaplatin treatment can be managed in an outpatient setting. On the basis of these advantages, nedaplatin has been used clinically in Japan as an alternative to cisplatin for patients with recurrent cervical cancer [10].

The radiosensitizing properties of nedaplatin have been demonstrated in several preclinical studies $[11,12]$. An in 
vitro investigation demonstrated that nedaplatin in combination with irradiation is highly effective for cervical cancer [12]. Although the preliminary data from clinical studies of the use of nedaplatin-based CCRT in patients with head and neck or esophageal cancer has been reported [13], however, the clinical experience with this agent in the setting of CCRT for cervical cancer patients is limited. As shown in Table 1, the use of concurrent weekly nedaplatin in patients with invasive cervical cancer in the setting of definitive radiotherapy was investigated in two Phase I [14, 15], two Phase II [16, 17] studies, and one retrospective study [18]; however, in the setting of adjuvant radiotherapy, nedaplatinbased CCRT has only been evaluated in one Phase I [19] and two retrospective studies $[20,21]$. Thus, it remains unclear whether nedaplatin-based CCRT is superior to RT alone in patients with cervical cancer.

Concurrent chemoradiotherapy, usually involving 40 $\mathrm{mg} / \mathrm{m}^{2}$ of weekly cisplatin, is accepted as the standard firstline treatment for cervical cancer [32, 33]. However, its nephrotoxicity and gastrointestinal toxicity may limit its use. In a previous Japanese Phase I study, which determined the recommended dose of weekly cisplatin in the setting of CCRT after radical hysterectomy, dose-limiting toxicity (DLT) was observed at $40 \mathrm{mg} / \mathrm{m}^{2}$, indicating that a weekly dose of $40 \mathrm{mg} / \mathrm{m}^{2}$ of cisplatin may be too high for Japanese patients with cervical cancer [34]. As nedaplatin exhibits minimal nephrotoxicity, it can be used in patients with marginal renal function $[4,5]$. Moreover, since nedaplatin does not require hydration and shows minimal gastrointestinal toxicity, nedaplatin treatment can be managed in an outpatient setting. Thus, the substitution of nedaplatin for cisplatin as a concurrent chemotherapy for patients with cervical cancer may be beneficial.

Recently, we investigated the efficacy of nedaplatinbased CCRT in the settings of adjuvant treatment after radical hysterectomy [18] and definitive radiotherapy [20]. Although they were retrospective in nature, to the best of our knowledge, these are the only reports that have demonstrated a significant improvement in the survival of cervical cancer patients treated with nedaplatin-based CCRT. In this review, we show the results of these retrospective analyses and provide information on the results of other clinical studies that investigated the efficacy of nedaplatin-based CCRT in patients with cervical cancer.

\section{Postoperative Concurrent Nedaplatin-Based Chemoradiotherapy in Patients with Early-Stage Cervical Cancer}

2.1. Background. Early-stage cervical cancer has traditionally been treated with either radical hysterectomy or primary radiotherapy, with similar survival outcomes [35]. Several risk factors have been identified that compromised the treatment outcome in patients with Early-stage cervical cancer who were primarily treated with radical surgery [36-38]. Generally, patients that demonstrate risk factors such as positive pelvic nodes, parametrial invasion, and

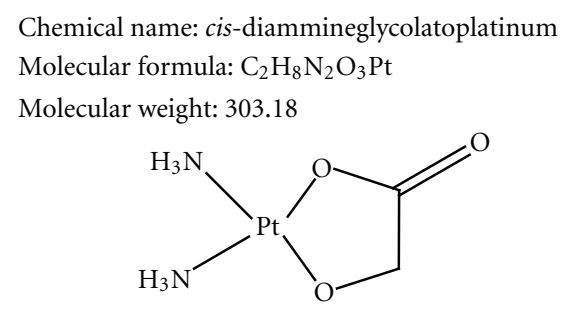

FIGURE 1: Chemical structure of nedaplatin.

a positive vaginal margin are regarded as "high-risk" for recurrence [36]. Moreover, patients with a tumor confined to the cervix that display risk factors such as a large tumor, lymph vascular space invasion, and deep stromal invasion are considered to be at "intermediate-risk" of recurrence [37, 38]. Postoperative RT is usually recommended for patients that display these risk factors.

A previous Gynecologic Oncology Group Phase III study (GOG 92) evaluated the role of adjuvant RT in patients that showed "intermediate-risk" prognostic factors, that is, those with at least two of the following risk factors after radical hysterectomy: $>1 / 3$ stromal invasion, lymph vascular space involvement, or a large tumor diameter. Although overall survival was not significantly prolonged by the addition of adjuvant RT, this study demonstrated that adjuvant RT significantly reduced the risk of recurrence and prolonged progression-free survival in these women $[39,40]$. However, the clinical benefit of postoperative CCRT in patients with Early-stage cervical cancer that displayed intermediate-risk prognostic factors has never been investigated in the setting of randomized clinical trials.

In early-stage cervical cancer patients demonstrating high-risk prognostic factors, a prospective randomized clinical trial (GOG 109/SWOG 87-97) examined the role of adjuvant cisplatin-based CCRT after radical hysterectomy and pelvic lymphadenectomy [41]. The study demonstrated that the addition of concurrent cisplatin-based chemotherapy to postoperative RT improved the survival of patients with positive pelvic $\mathrm{LN}$ and/or a positive resection margin and/or parametrial involvement.

Thus, it remains unclear whether postoperative nedaplatin-based CCRT is superior to RT alone in patients with Early-stage cervical cancer that displayed intermediateor high-risk prognostic factors.

To answer this question, we retrospectively evaluated the effectiveness of nedaplatin-based CCRT in 145 Japanese patients with FIGO Stage IA2-IIB cervical cancer after radical hysterectomy and pelvic lymphadenectomy [18].

2.2. Clinical Findings. As shown in Tables 2 and 3, among the patients enrolled in the study, 57 showed intermediaterisk prognostic factors such as deep stromal invasion, capillary lymphatic space involvement, or a large tumor diameter. Sixty-eight patients displayed high-risk prognostic factors such as positive pelvic lymph nodes, parametrial involvement, or a positive surgical margin. These patients were postoperatively treated with either CCRT or RT alone. 
TABLE 1: Summery of the literature on nedaplatin-based concurrent chemoradiotherapy.

\begin{tabular}{|c|c|c|c|c|c|}
\hline Author (Reference) & Year & Study type & Setting & Stage & Results \\
\hline J. Kodama [19] & 2008 & Phase I & Postoperative RT & Ib-IIb & $\begin{array}{l}\text { Weekly } 35 \mathrm{mg} / \mathrm{m}^{2} \text { of nedaplatin was } \\
\text { recommended. }\end{array}$ \\
\hline Y. Kobayashi [21] & 2009 & Retro & Postoperative RT & Ib2-IIb & $\begin{array}{l}\text { Biweekly } 70 \mathrm{mg} / \mathrm{m}^{2} \text { of nedaplatin was } \\
\text { employed. CCRT was better than RT } \\
\text { alone, but the improvement was not } \\
\text { significant. }\end{array}$ \\
\hline S. Mabuchi [20] & 2009 & Retro & Postoperative RT & IA2-IIb & $\begin{array}{l}\text { Weekly } 40 \mathrm{mg} / \mathrm{m}^{2} \text { of nedaplatin was } \\
\text { employed. } \\
\text { CCRT was significantly better than RT } \\
\text { alone. }\end{array}$ \\
\hline Y. Onishi [14] & 2002 & Phase I & Definitive RT & III-IVa & $\begin{array}{l}\text { Weekly } 30 \mathrm{mg} / \mathrm{m}^{2} \text { of nedaplatin was } \\
\text { recommended. }\end{array}$ \\
\hline K. Yoshinaga [15] & 2007 & Phase I & Definitive RT & Ib2-IIIb & $\begin{array}{l}\text { Weekly } 35 \mathrm{mg} / \mathrm{m}^{2} \text { of nedaplatin was } \\
\text { recommended. }\end{array}$ \\
\hline Y. Yokoyama [16] & 2008 & Phase II & Definitive RT & Ib2-IVa & $\begin{array}{l}\text { Weekly } 30 \mathrm{mg} / \mathrm{m}^{2} \text { of nedaplatin was } \\
\text { employed. }\end{array}$ \\
\hline Y. Niibe [17] & 2008 & Phase II & Definitive RT & IIIa-IVa & $\begin{array}{l}\text { Weekly } 30 \mathrm{mg} / \mathrm{m}^{2} \text { of nedaplatin was } \\
\text { employed. }\end{array}$ \\
\hline S. Mabuchi [18] & 2010 & Retro & Definitive RT & IIIb & $\begin{array}{l}\text { Weekly } 35 \mathrm{mg} / \mathrm{m}^{2} \text { of nedaplatin was } \\
\text { employed. } \\
\text { CCRT was significantly better than RT } \\
\text { alone. }\end{array}$ \\
\hline
\end{tabular}

CCRT: concurrent chemoradiotherapy, Retro: retrospective cohort study, RT: radiotherapy.

TABLE 2: Patient characteristics and treatment outcomes (Intermediate-risk patients).

\begin{tabular}{|c|c|c|c|c|c|}
\hline & & & RT-group & CCRT-group & $P$-value \\
\hline \multirow{10}{*}{ Patient characteristics } & Number of patients & & 35 & 22 & \\
\hline & Age (mean) & & 49.8 & 49.6 & \\
\hline & \multirow{4}{*}{ Clinical stage } & IA2 & 0 & 0 & \\
\hline & & IB & 25 & 18 & \\
\hline & & IIA & 10 & 4 & \\
\hline & & IIB & 0 & 0 & \\
\hline & \multirow{4}{*}{ Histology } & Squamous cell & 27 & 13 & \\
\hline & & Adenocarcinoma & 5 & 0 & \\
\hline & & Adenosquamous & 3 & 9 & \\
\hline & & Others & 0 & 0 & \\
\hline \multirow{4}{*}{ Treatment outcome } & Duration of radiotherapy & Days & 37 & 37 & NS \\
\hline & Patients with recurrence (\%) & & $12(34.3)$ & $1(4.5)$ & .01 \\
\hline & PFS (months) & Mean & 29 & 36 & .0026 \\
\hline & OS (months) & Mean & 32.5 & 36 & .0430 \\
\hline
\end{tabular}

PFS: progression-free survival, OS: overall survival, CCRT: concurrent chemoradiotherapy, RT: radiotherapy.

The optimal dose of concurrent weekly nedaplatin has not been well established in the setting of adjuvant therapy because nedaplatin-based adjuvant CCRT has only been prospectively evaluated in one Phase I study [19], in which the authors recommended $35 \mathrm{mg} / \mathrm{m}^{2}$ nedaplatin for 5 weeks as a standard treatment regimen (Table 1 ). However, since weekly $40 \mathrm{mg} / \mathrm{m}^{2}$ of cisplatin in combination with pelvic radiotherapy has been established as a standard treatment for cervical cancer, moreover, since the antitumor activity of nedaplatin has been reported to be similar to that of cisplatin $[2,3,8]$, we have employed $40 \mathrm{mg} / \mathrm{m}^{2}$ of weekly nedaplatin for 5 weeks as a standard regimen for adjuvant CCRT in our clinical practice.

Overall, nedaplatin-based CCRT was well tolerated. There were no treatment-related deaths, and all patients completed the planned pelvic RT. As shown in Table 4, among a total of 56 patients treated with CCRT, grade 3 or 4 acute toxicities were observed in 36 patients (64.3\%). Of these, thirty patients had neutropenia alone and three had both neutropenia and thrombocytopenia. Three patients developed nonhematologic toxicities (bowel obstruction in one patient, diarrhea in one patient, radiation dermatitis 
TABle 3: Patient characteristics and treatment outcomes (High-risk patients).

\begin{tabular}{|c|c|c|c|c|c|}
\hline & & & RT-group & CCRT-group & $P$-value \\
\hline \multirow{10}{*}{ Patient characteristics } & Number of patients & & 34 & 34 & \\
\hline & Age (mean) & & 51.3 & 50.1 & \\
\hline & \multirow{4}{*}{ Clinical stage } & IA2 & 0 & 0 & \\
\hline & & IB & 7 & 12 & \\
\hline & & IIA & 9 & 2 & \\
\hline & & IIB & 18 & 20 & \\
\hline & \multirow{4}{*}{ Histology } & Squamous cell & 21 & 25 & \\
\hline & & Adenocarcinoma & 13 & 8 & \\
\hline & & Adenosquamous & 0 & 1 & \\
\hline & & Others & 0 & 0 & \\
\hline \multirow{4}{*}{ Treatment outcome } & Duration of radiotherapy & Days & 38 & 38 & NS \\
\hline & Patients with recurrence (\%) & & $16(47.0)$ & $9(26.5)$ & NS \\
\hline & PFS (months) & Mean & 22.6 & 29.5 & NS \\
\hline & OS (months) & Mean & 29.7 & 34.2 & .0364 \\
\hline
\end{tabular}

PFS: progression-free survival, OS: overall survival, CCRT: concurrent chemoradiotherapy, RT: radiotherapy.

TABLE 4: Grade 3-4 toxicities (acute and late toxicities).

\begin{tabular}{|c|c|c|c|c|}
\hline & & & $\begin{array}{l}\text { CCRT-group } \\
(n=56)\end{array}$ & $\begin{array}{l}\text { RT-group } \\
(n=69)\end{array}$ \\
\hline \multirow{7}{*}{ Acute } & $\begin{array}{l}\text { Number of patients with Grade 3-4 acute } \\
\text { toxicity }(\%)\end{array}$ & & $36(64.3)$ & $8(11.6)$ \\
\hline & \multirow{3}{*}{ Hematologic } & Neutropenia & 30 & 4 \\
\hline & & Thrombocytopenia & 3 & 0 \\
\hline & & Neutropenia + Thrombocytopenia & 3 & 1 \\
\hline & \multirow{3}{*}{ Nonhematologic } & Bowel obstruction & 1 & 1 \\
\hline & & Diarrhea & 1 & 2 \\
\hline & & Dermatitis & 1 & 0 \\
\hline \multirow[t]{2}{*}{ Late } & $\begin{array}{l}\text { Number of patients with Grade 3-4 late } \\
\text { toxicity }(\%)\end{array}$ & & 0 & $1(1.8)$ \\
\hline & & Vesicovaginal fistula & 0 & 1 \\
\hline
\end{tabular}

RT: radiotherapy, CCRT: concurrent chemoradiotherapy.

TABle 5: Patient characteristics and treatment outcomes.

\begin{tabular}{|c|c|c|c|c|c|}
\hline & & & RT-group & CCRT-group & $P$-value \\
\hline \multirow{6}{*}{ Patient characteristics } & Number of patients & & 21 & 20 & \\
\hline & Median age & & 67 & 59 & \\
\hline & \multirow{2}{*}{ Histology } & SCC & 21 & 20 & \\
\hline & & Others & 0 & 0 & \\
\hline & Dose of nedaplatin administered, $\mathrm{mg} / \mathrm{m}^{2}$ & Median (range) & - & $35(10-45)$ & \\
\hline & Courses of nedaplatin administered & Median (range) & 一 & $5(2-5)$ & \\
\hline \multirow{8}{*}{ Treatment outcome } & \multirow{2}{*}{ PFS, months } & Median (range) & $7(0-60)$ & $60(0-60)$ & .0015 \\
\hline & & Mean & 21.4 & 43.3 & \\
\hline & \multirow{2}{*}{ OS, months } & Median & $29(1-60)$ & $60(5-60)$ & .0364 \\
\hline & & Mean & 32.3 & 47 & \\
\hline & Duration of radiotherapy & Median (range) & $47(41-61)$ & $45(40-57)$ & NS \\
\hline & Patients with recurrence $(\%)$ & & $14(66.7 \%)$ & $7(35 \%)$ & NS \\
\hline & Patients with grade $3-4$ acute toxicity (\%) & & $1(4.8 \%)$ & $10(50 \%)$ & .0014 \\
\hline & Patients with grade 3-4 late toxicity (\%) & & $0(0 \%)$ & $2(10 \%)$ & NS \\
\hline
\end{tabular}

PFS: progression-free survival, OS: overall survival, SCC: squamous cell carcinoma, CCR: concurrent chemoradiotherapy, RT: radiotherapy. 
TABLE 6: Literature review: survival, treatment failure, and complications.

\begin{tabular}{|c|c|c|c|c|c|c|c|c|c|}
\hline Author (Reference) & Year & $\begin{array}{l}\text { Study } \\
\text { type }\end{array}$ & $\begin{array}{l}\begin{array}{l}\text { Concurrent } \\
\text { chemotherapy }\end{array} \\
\end{array}$ & Brachytherapy & Stage & Followup & $\begin{array}{c}\text { Overall } \\
\text { Survival (\%) }\end{array}$ & $\begin{array}{c}\text { Treatment } \\
\text { Failure (\%) } \\
\end{array}$ & $\begin{array}{c}\text { Late toxicity } \\
\text { (grade 3-4) (\%) }\end{array}$ \\
\hline T. Teshima [22] & 1993 & RCT & - & HDR & III & 5 years & 53 & 47 & 10 \\
\hline M. Hareyama [23] & 2002 & RCT & - & HDR & III & 5 years & 69 & 49 & 7 \\
\hline $\begin{array}{l}\text { P. } \\
\text { Lertsanguansinchai } \\
{[24]}\end{array}$ & 2004 & RCT & - & HDR & IIIb & 3 years & 71 & 30 & 7 \\
\hline M. Morris [25] & 1999 & RCT & Cisplatin & LDR & III-IVa & 5 years & 63 & 42 & 12 \\
\hline P. G. Rose [26] & 1999 & RCT & Cisplatin & LDR & II-IVa & 4 years & 66 & 38 & 1.7 \\
\hline T. Toita [27] & 2005 & Retro & Cisplatin & HDR & I-III & 3 years & 79 & 33 & 2 \\
\hline Y. L. Chung [28] & 2005 & $\begin{array}{l}\text { Phase } \\
\text { I/II }\end{array}$ & Cisplatin & HDR & IIb-IVa & 3 years & 83 & 19 & 6 \\
\hline S. W. Chen [29] & 2006 & Retro & Cisplatin & HDR & IIb-III & 4 years & 74 & 46 & 14 \\
\hline R. Potter [30] & 2006 & Retro & Cisplatin & HDR & Ib-IVa & 3 years & 61 & 44 & 4 \\
\hline P. Novetsky [31] & 2007 & Retro & Cisplatin & HDR & III-IV & 5 years & 65 & 35 & 6 \\
\hline S. Mabuchi [20] & 2010 & Retro & Nedaplatin & HDR & IIIb & 5 years & 65 & 35 & 10 \\
\hline
\end{tabular}

RCT: randomized controlled study, Retro: retrospective study, HDR: high-dose rate brachytherapy, LDR: low-dose rate brachytherapy.

in one patient). Among a total of 69 patients treated with RT alone, grade 3 or 4 acute toxicities were observed in 8 patients $(11.6 \%)$. Of these, four patients had neutropenia alone and one had both neutropenia and thrombocytopenia. Three patients developed nonhematologic toxicities (bowel obstruction in one patient, diarrhea in two patients.). When compared, the frequency of acute grade 3-4 acute toxicities observed in patients treated with CCRT was significantly higher than that observed in the RT-group $(P<.001)$. Nevertheless, there were no significant differences in the length of radiotherapy among these treatment groups (Table 2 and 3 ). In this study, severe late complications were only observed in a patient treated with RT (Table 4). This woman developed a vesicovaginal fistula 4 months after the completion of RT. No Grade 3-4 late toxicity was observed in the patients treated with CCRT, which may indicate that the addition of concurrent weekly nedaplatin to pelvic RT does not increase late toxicity.

In the intermediate-risk group, when the CCRT-group was compared with the RT-group, as shown in Table 2 and Figure 2, CCRT was significantly superior in terms of recurrence rate $(P=.01)$, PFS (log-rank; $P=.0026$ ), and OS (log-rank; $P=.0435)$. Moreover, as shown in Table 3 and Figure 3, in the patients that displayed high-risk prognostic factors, the addition of concurrent nedaplatinbased chemotherapy also resulted in an improved outcome in terms of OS ( $\log$-rank; $P=.0364$ ).

In conclusion, our retrospective investigation demonstrated that the concurrent use of weekly nedaplatin with pelvic RT is safe and improves survival outcome in earlystage cervical cancer patients that display intermediate- or high-risk prognostic factors. Moreover, these results indicate that nedaplatin-based adjuvant CCRT can be considered as an alternative to cisplatin-based adjuvant CCRT.

\section{Concurrent Nedaplatin-Based Chemoradiotherapy in Patients with FIGO Stage IIIb Cervical Cancer}

3.1. Background. Radiotherapy is the major treatment modality for invasive cervical cancer and has achieved significantly improved treatment outcomes; however, substantial treatment failure still occurs, especially in advanced-stage patients [42].

One of the major clinical limitations in the management of advanced-stage disease is the size of the tumor. The tumor volume in patients with advanced-stage disease is usually large. It is generally accepted that the ability of radiotherapy to cure locally advanced cervical cancer is limited by the size of the tumor because the dose required to treat a large tumor exceeds the limit of toxicity in normal tissue [43]. Therefore, efforts to maximize local control and improve survival are necessary.

For this purpose, various clinical studies have evaluated the survival benefit of adding concurrent chemotherapy. When added to pelvic RT, cisplatin was found to reduce the risk of death from cervical cancer by approximately $50 \%$ $[25,26,44,45]$; however, its effects in patients with stage III or greater disease are far from optimal. According to a recent review of 18 clinical trials, the absolute 5-year survival increase was 10\% (Stage IA-IIA), 7\% (Stage IIb), and 3\% (Stage III-IVa) [46]. Therefore, other therapeutic approaches must be tested in order to further improve outcomes.

An important problem in the management of patients with advanced-stage cervical cancer is the presence of hydronephrosis as a result of ureteral obstruction caused by parametrial disease. It has previously been reported that the presence of hydronephrosis is an important indicator of a poor prognosis [47]. The precise incidence of ureteral 


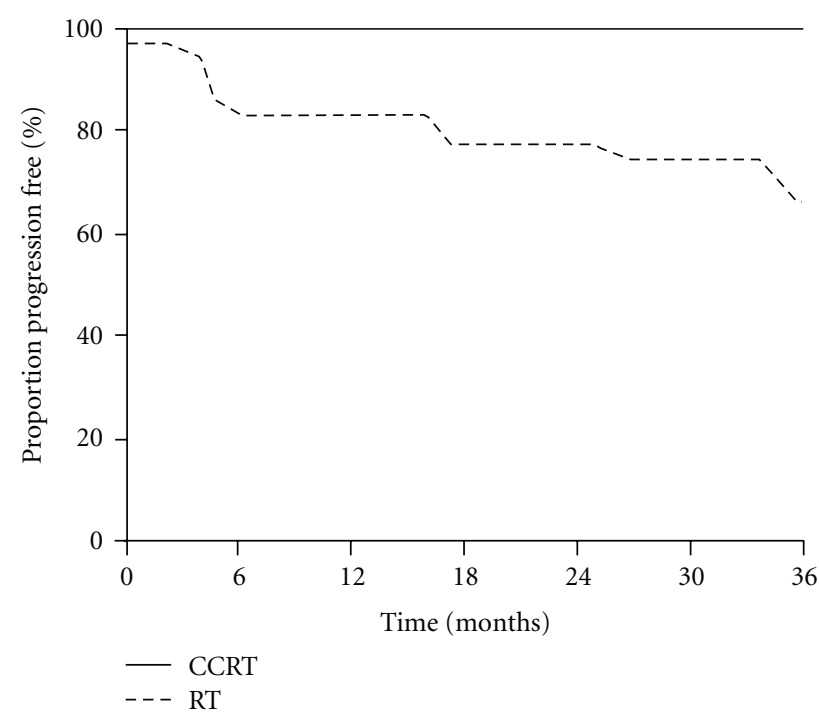

(a)

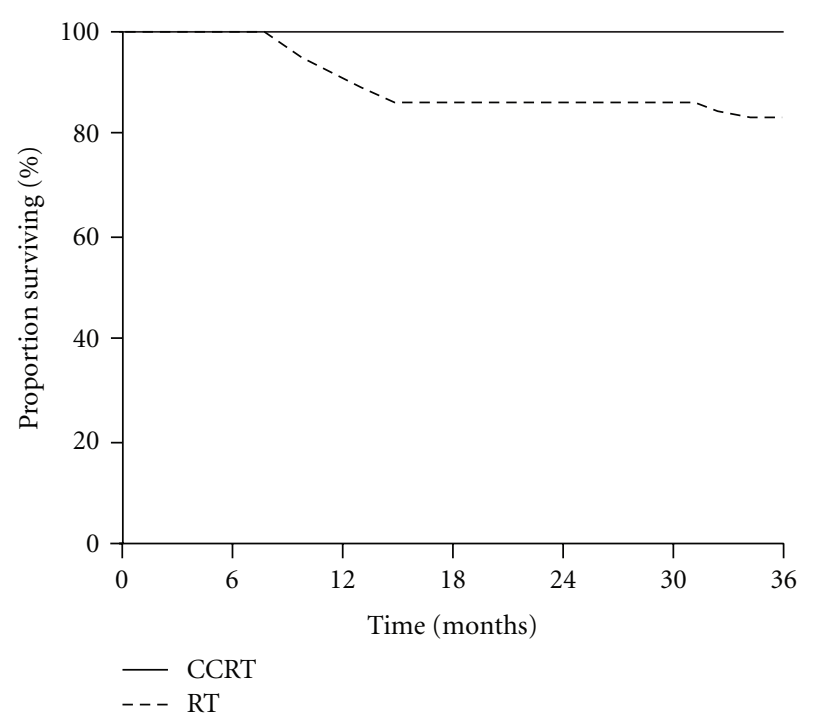

(b)

Figure 2: Progression-free survival (a) and overall survival (b) in intermediate-risk patients.

obstruction is unknown, but it is reported to be $55.8 \%$ among patients with stage III-IV disease [47]. Although weekly cisplatin during RT has been reported to be well tolerated, its nephrotoxicity may limit its use for advanced-stage cervical cancer patients, especially in patients with impaired renal function due to ureteral obstruction. Therefore, the use of an agent such as nedaplatin that shows less nephrotoxicity as a radiosensitizer may improve the outcomes of these patients.

Based on the US National Cancer Institute (NCI) alert in 1999 [48], we have started the clinical use of nedaplatinbased CCRT using HDR-ICBT to determine if concurrent nedaplatin is a suitable alternative to cisplatin in patients with cervical cancer.

Recently, we conducted a retrospective analysis to evaluate whether nedaplatin-based CCRT is safe and superior to RT alone in Japanese patients with FIGO stage IIIb cervical cancer [20].

3.2. Clinical Findings. As shown in Table 5, 41 women with FIGO Stage IIIb cervical cancer were treated with either nedaplatin-based CCRT $(n=20)$ or RT alone $(n=21)$.

Among the patients treated with CCRT, the median dose of nedaplatin administered was $35 \mathrm{mg} / \mathrm{m}^{2}$, and the median number of courses of nedaplatin was five. The optimal dose of concurrent weekly nedaplatin for patients with invasive cervical cancer treated by primary CCRT using EBRT and HDR-ICBT is still unknown, but has previously been investigated in several prospective clinical studies [14-17]. Of these, three studies recommended $30 \mathrm{mg} / \mathrm{m}^{2}$, and the other recommended $35 \mathrm{mg} / \mathrm{m}^{2}$ nedaplatin as a standard treatment regimen (Table 1). Therefore, the dose of nedaplatin utilized in our study was consistent with these previous studies.

Overall, nedaplatin-based CCRT was well tolerated. All patients completed the planned EBRT and HDR-ICBT.
As shown in Table 5, grade 3 or 4 acute toxicities were observed in 10 patients (50\%) in the CCRT-group. The most frequently observed acute toxicity was neutropenia or a combination of neutropenia and thrombocytopenia. The overall incidence of grade 3-4 acute toxicities was significantly higher in the CCRT-group than in the RTgroup. However, there were no significant differences in the duration of radiotherapy among these treatment groups (Table 5).

With regard to radiotherapy using EBRT and LDR-ICBT, late toxicity from concurrent chemotherapy has been examined previously (Table 6), and no differences were found in the rates of bowel or bladder toxicity between the patients treated with RT alone and those treated with CCRT [49]. However, because of the lack of a controlled clinical study, it is not clear whether concurrent chemotherapy increases the incidence of late toxicity in the setting of radiotherapy using EBRT and HDR-ICBT. In our study, severe late complications were observed in two patients $(10 \%)$ treated with CCRT. As shown in Table 5, the rate of severe late complications in the CCRT-group (10\%) was similar to those of other series in which the patients had been treated with EBRT and HDR-ICBT without concurrent chemoradiotherapy [2224], cisplatin-based CCRT using EBRT and LDR-ICBT [25, 26], or cisplatin-based CCRT using EBRT and HDR-ICBT [27-31]. Collectively, these results (including ours) suggest that the addition of concurrent weekly nedaplatin to EBRT and HDR-ICBT does not increase late toxicity.

When the CCRT-group was compared with the RTgroup, as shown in Figure 4 and Table 5, CCRT was found to be significantly superior in terms of PFS (log-rank; $P=$ .0015 ) and OS (log-rank; $P=.0364$ ), and the risk of death was decreased by $46 \%$ by the addition of nedaplatinbased concurrent chemotherapy. These results indicate that the addition of concurrent nedaplatin to pelvic EBRT plus 


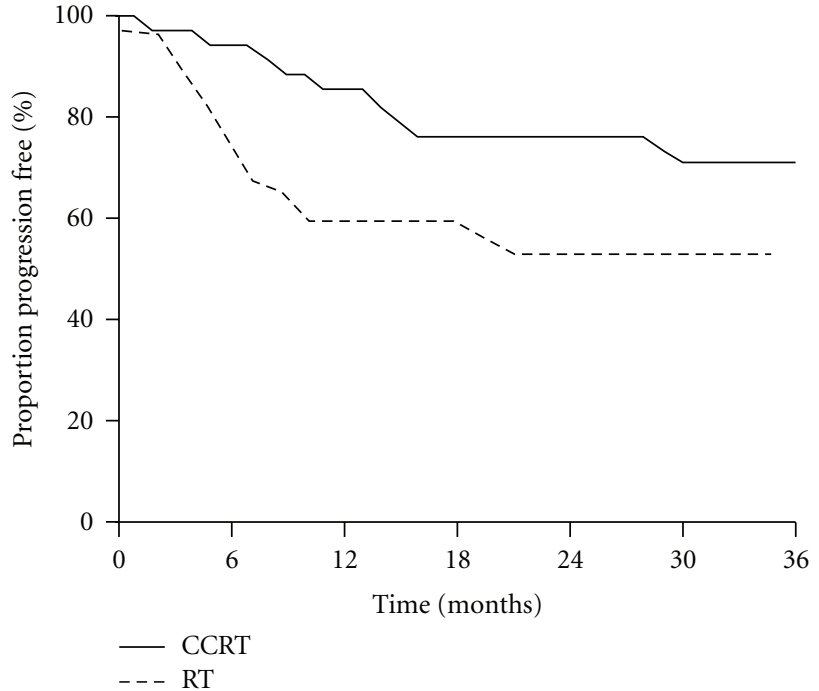

(a)

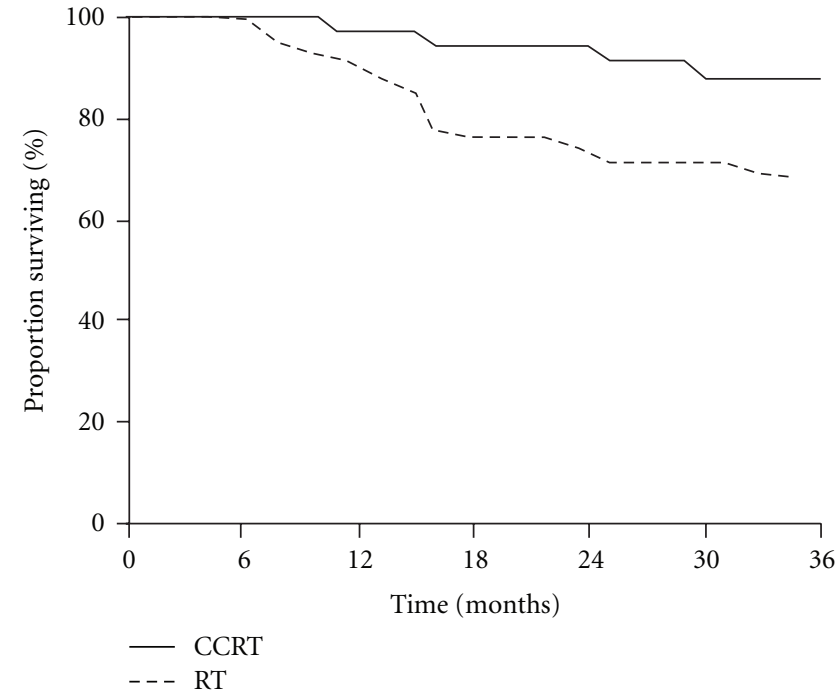

(b)

FIGURE 3: Progression-free survival (a) and overall survival (b) in high-risk patients.

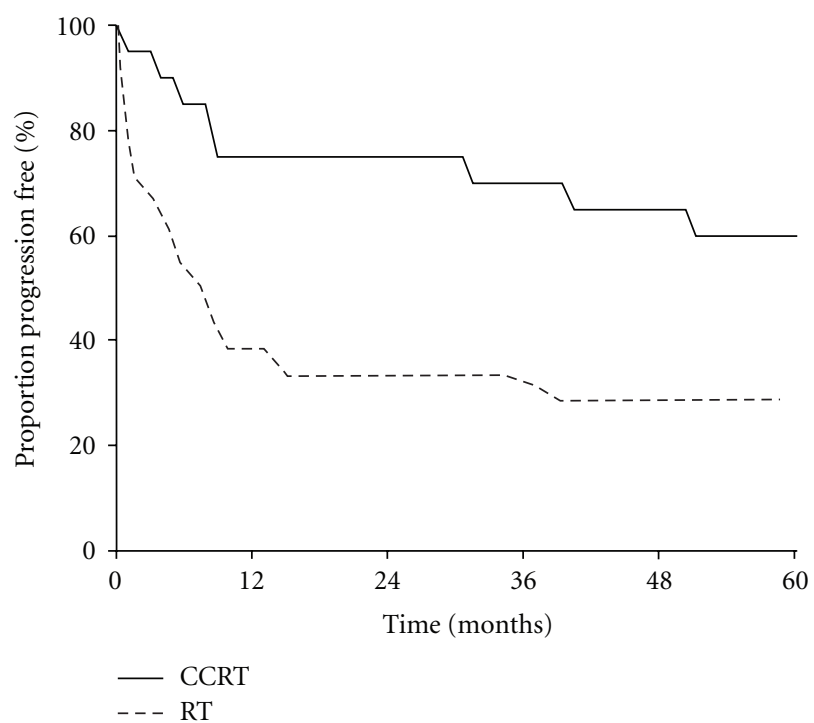

(a)

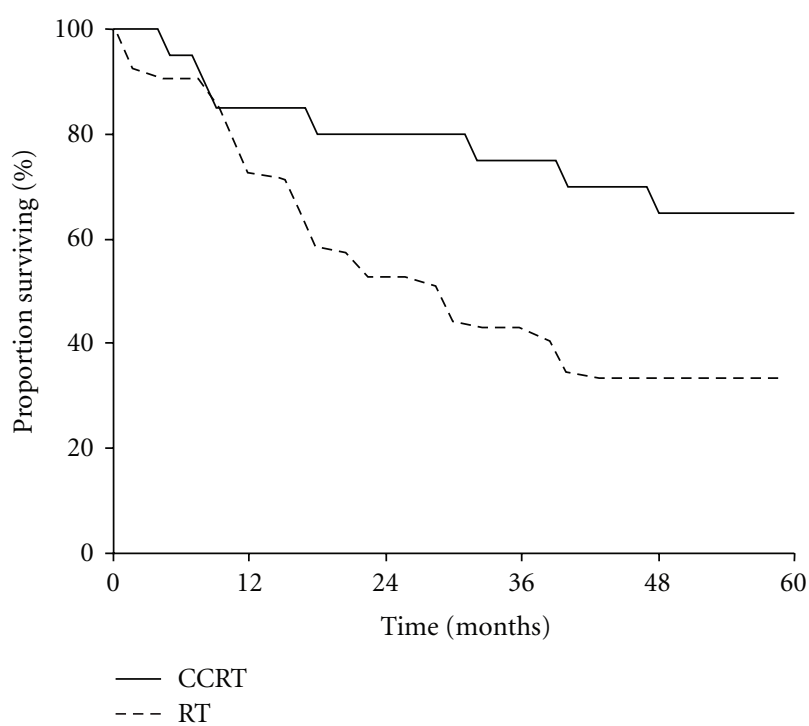

(b)

FIgURE 4: Progression-free survival (a) and overall survival (b) among patients in the CCRT- and RT-groups.

HDR-ICBT significantly improved the prognosis of this patient population. The 5-year overall survival rate of $65 \%$ and the treatment failure rate of $35 \%$ found in our study are comparable to those demonstrated in previous clinical studies of cisplatin-based CCRT (Table 6). These results suggest that in this patient population nedaplatin can be considered as an alternative to cisplatin in the setting of chemoradiotherapy.

3.3. Future Directions and Prospects. Although the addition of concurrent nedaplatin-based chemotherapy to pelvic RT resulted in improved survival in our studies, a significant number of cervical cancer patients still suffered recurrence and died of their disease. Therefore, to further improve the prognosis of these patients, novel treatment strategies such as the use of nedaplatin-based combination chemotherapy as a radiosensitizer, the coadministration of nedaplatin with molecularly targeted agents, improved drug delivery strategies using delivery vehicles such as liposomes, or more conformal dose distributions with intensity-modulated RT need to be investigated in future trials.

In contrast to cisplatin-based CCRT, due to the lack of prospective randomized studies, nedaplatin-based CCRT has not been convincingly proven to be clinically effective for the treatment of cervical cancer. However, given the advantage of patient's tolerance as well as its significant 
activity demonstrated in these studies, we believe that nedaplatin-based CCRT is a reasonable treatment option for this patient population. To definitively demonstrate the activity of nedaplatin-based CCRT, further investigation in a randomized controlled trial, for example, to compare concurrent nedaplatin versus cisplatin in the setting of CCRT, is warranted.

\section{Conflict of Interests}

The authors declare that they have no conflicts of interest.

\section{Abbreviations}

$\begin{array}{ll}\text { OS: } & \text { Overall survival } \\ \text { PFS: } & \text { Progression-free interval } \\ \text { ICBT: } & \text { Intracavitary brachytherapy } \\ \text { HDR: } & \text { High dose rate } \\ \text { LDR: } & \text { Low dose rate } \\ \text { EBRT: } & \text { External beam radiotherapy } \\ \text { RT: } & \text { Radiotherapy } \\ \text { CCRT: } & \text { Concurrent chemoradiotherapy. }\end{array}$

\section{Acknowledgment}

The authors thank Remina Emoto for providing secretarial assistance.

\section{References}

[1] F. Kanzawa, Y. Matsushima, H. Nakano et al., "Antitumor activity of a new platinum compound (glycolate o,o') diammineplatinum (II) (254-S), against non-small cell lung carcinoma grown in a human tumor clonogenic assay system," Anticancer Research, vol. 8, no. 3, pp. 323-327, 1988.

[2] B. J. Monk, D. S. Alberts, R. A. Burger et al., "In vitro phase II comparison of the cytotoxicity of a novel platinum analog, nedaplatin (254-S), with that of cisplatin and carboplatin against fresh, human cervical cancers," Gynecologic Oncology, vol. 71, no. 2, pp. 308-312, 1998.

[3] Y. Sasaki, T. Shinkai, K. Eguchi et al., "Prediction of the antitumor activity of new platinum analogs based on their ex vivo pharmacodynamics as determined by bioassay," Cancer Chemotherapy and Pharmacology, vol. 27, no. 4, pp. 263-270, 1991.

[4] T. Uehara, H. Watanabe, F. Itoh et al., "Nephrotoxicity of a novel antineoplastic platinum complex, nedaplatin: a comparative study with cisplatin in rats," Archives of Toxicology, vol. 79, no. 8, pp. 451-460, 2005.

[5] Y. Kawai, S. Taniuchi, S. Okahara, M. Nakamura, and M. Gemba, "Relationship between cisplatin or nedaplatininduced nephrotoxicity and renal accumulation," Biological and Pharmaceutical Bulletin, vol. 28, no. 8, pp. 1385-1388, 2005.

[6] M. Fukuda, T. Shinkai, K. Eguchi et al., "Phase II study of (glycolate-O,O') diammineplatinum(II), a novel platinum complex, in the treatment of non-small-cell lung cancer," Cancer Chemotherapy and Pharmacology, vol. 26, no. 6, pp. 393-396, 1990.

[7] Y. Inuyama, H. Miyake, M. Horiuchi, K. Hayasaki, S. Komiyama, and K. Ota, "An early phase II clinical study of cis-diammine glycolato platinum, 254-S, for head and neck cancers," Japanese Journal of Cancer and Chemotherapy, vol. 19, no. 6, pp. 863-869, 1992.

[8] T. Kato, H. Nishimura, M. Yakushiji et al., "Phase II study of 254-S (cis-diammine glycolato platinum) for gynecological cancer," Gan To Kagaku Ryoho, vol. 19, pp. 695-701, 1992.

[9] N. Yamamoto, T. Tamura, T. Kurata et al., "A dose-finding and pharmacokinetic study of nedaplatin in elderly patients with advanced non-small cell lung cancer," Cancer Chemotherapy and Pharmacology, vol. 65, no. 1, pp. 79-88, 2009.

[10] S. Mabuchi, K. Morishige, M. Fujita et al., "The activity of carboplatin and paclitaxel for recurrent cervical cancer after definitive radiotherapy," Gynecologic Oncology, vol. 113, no. 2, pp. 200-204, 2009.

[11] Y. Nakamura, M. Hasegawa, K. Hayakawa et al., "Induction of p53-dependent apoptosis in vivo by nedaplatin and ionizing radiation," Oncology Reports, vol. 7, no. 2, pp. 261-265, 2000.

[12] T. Tanaka, K. Yukawa, and N. Umesaki, "Radiation reduces carboplatin sensitivity and enhances nedaplatin sensitivity in cervical squamous cell carcinoma in vitro," European Journal of Gynaecological Oncology, vol. 28, no. 5, pp. 352-355, 2007.

[13] Y. Sato, T. Takayama, T. Sagawa et al., "A phase I/II study of nedaplatin and 5-fluorouracil with concurrent radiotherapy in patients with esophageal cancer," Cancer Chemotherapy and Pharmacology, vol. 58, no. 5, pp. 570-576, 2006.

[14] Y. Onishi, T. Nakamura, M. Hatae, S. Adachi, and T. Ogasawara, "Phase I study of weekly and radiation therapy for advanced cervical cancer," Proceedings of the American Society of Clinical Oncology, vol. 21, article 111b, 2002.

[15] K. Yoshinaga, H. Niikura, Y. Ogawa et al., "Phase I trial of concurrent chemoradiation with weekly nedaplatin in patients with squamous cell carcinoma of the uterine cervix," Gynecologic Oncology, vol. 104, no. 1, pp. 36-40, 2007.

[16] Y. Yokoyama, T. Takano, K. Nakahara et al., "A phase II multicenter trial of concurrent chemoradiotherapy with weekly nedaplatin in advanced uterine cervical carcinoma: Tohoku gynecologic cancer unit study," Oncology Reports, vol. 19, no. 6, pp. 1551-1556, 2008.

[17] Y. Niibe, S. Tsunoda, T. Jobo et al., "Phase II study of radiation therapy combined with weekly nedaplatin in locally advanced uterine cervical carcinoma (LAUCC): Kitasato Gynecologic Radiation Oncology Group (KGROG 0501)_initial analysis," European Journal of Gynaecological Oncology, vol. 29, no. 3, pp. 222-224, 2008.

[18] S. Mabuchi, K.-I. Morishige, F. Isohashi et al., "Postoperative concurrent nedaplatin-based chemoradiotherapy improves survival in early-stage cervical cancer patients with adverse risk factors," Gynecologic Oncology, vol. 115, no. 3, pp. 482487, 2009.

[19] J. Kodama, M. Takemoto, N. Seki et al., "Phase I study of weekly nedaplatin and concurrent pelvic radiotherapy as adjuvant therapy after radical surgery for cervical cancer," International Journal of Gynecological Cancer, vol. 18, no. 5, pp. 1037-1041, 2008.

[20] S. Mabuchi, H. Ugaki, F. Isohashi et al., "Concurrent weekly nedaplatin, external beam radiotherapy and high-dose-rate brachytherapy in patients with FIGO stage IIIb cervical cancer: a comparison with a cohort treated by radiotherapy alone," Gynecologic and Obstetric Investigation, vol. 69, no. 4, pp. 224232, 2010.

[21] Y. Kobayashi, T. Ohara, Y. Wada et al., "Concurrent chemoradiotherapy with nedaplatin after radical hysterectomy in patients with stage IB and II cervical cancer," Journal of 
Obstetrics and Gynaecology Research, vol. 35, no. 3, pp. 490494, 2009.

[22] T. Teshima, T. Inoue, H. Ikeda et al., "High-dose rate and lowdose rate intracavitary therapy for carcinoma of the uterine cervix: final results of Osaka University Hospital," Cancer, vol. 72, no. 8, pp. 2409-2414, 1993.

[23] M. Hareyama, K.-I. Sakata, A. Oouchi et al., "High-dose-rate versus low-dose-rate intracavitary therapy for carcinoma of the uterine cervix: a randomized trial," Cancer, vol. 94, no. 1, pp. 117-124, 2002.

[24] P. Lertsanguansinchai, C. Lertbutsayanukul, K. Shotelersuk et al., "Phase III randomized trial comparing LDR and HDR brachytherapy in treatment of cervical carcinoma," International Journal of Radiation Oncology Biology Physics, vol. 59, no. 5, pp. 1424-1431, 2004.

[25] M. Morris, P. J. Eifel, J. Lu et al., "Pelvic radiation with concurrent chemotherapy compared with pelvic and paraaortic radiation for high-risk cervical cancer," The New England Journal of Medicine, vol. 340, no. 15, pp. 1137-1143, 1999.

[26] P. G. Rose, B. N. Bundy, E. B. Watkins et al., "Concurrent cisplatin-based radiotherapy and chemotherapy for locally advanced cervical cancer," The New England Journal of Medicine, vol. 340, no. 15, pp. 1144-1153, 1999.

[27] T. Toita, H. Moromizato, K. Ogawa et al., "Concurrent chemoradiotherapy using high-dose-rate intracavitary brachytherapy for uterine cervical cancer," Gynecologic Oncology, vol. 96, no. 3, pp. 665-670, 2005.

[28] Y.-L. Chung, J. J.-M. Jian, S. H. Cheng et al., "Extended-field radiotherapy and high-dose-rate brachytherapy with concurrent and adjuvant cisplatin-based chemotherapy for locally advanced cervical cancer: a phase I/II study," Gynecologic Oncology, vol. 97, no. 1, pp. 126-135, 2005.

[29] S.-W. Chen, J.-A. Liang, Y.-C. Hung et al., "Concurrent weekly cisplatin plus external beam radiotherapy and high-dose rate brachytherapy for advanced cervical cancer: a control cohort comparison with radiation alone on treatment outcome and complications," International Journal of Radiation Oncology Biology Physics, vol. 66, no. 5, pp. 1370-1377, 2006.

[30] R. Pötter, J. Dimopoulos, B. Bachtiary et al., “3D conformal HDR-brachy- and external beam therapy plus simultaneous cisplatin for high-risk cervical cancer: clinical experience with 3 year follow-up," Radiotherapy and Oncology, vol. 79, no. 1, pp. 80-86, 2006.

[31] A. P. Novetsky, M. H. Einstein, G. L. Goldberg et al., "Efficacy and toxicity of concomitant cisplatin with external beam pelvic radiotherapy and two high-dose-rate brachytherapy insertions for the treatment of locally advanced cervical cancer," Gynecologic Oncology, vol. 105, no. 3, pp. 635-640, 2007.

[32] P. G. Rose, "Chemoradiotherapy: the new standard care for invasive cervical cancer," Drugs, vol. 60, no. 6, pp. 1239-1244, 2000.

[33] "National Comprehensive Cancer Network Clinical Practice Guidelines in Oncology, Cervical Cancer v.1," 2010, http:// www.nccn.org/professionals/physician_gls/PDF/cervical.pdf.

[34] Y. Watanabe, H. Nakai, M. Shimaoka, T. Tobiume, I. Tsuji, and H. Hoshiai, "Feasibility of concurrent cisplatin use during primary and adjuvant chemoradiation therapy: a phase I study in Japanese patients with cancer of the uterine cervix," International Journal of Clinical Oncology, vol. 11, no. 4, pp. 309-313, 2006.
[35] F. Landoni, A. Maneo, A. Colombo et al., "Randomised study of radical surgery versus radiotherapy for stage Ib-IIa cervical cancer," The Lancet, vol. 350, no. 9077, pp. 535-540, 1997.

[36] R. A. K. Samlal, J. van der Velden, M. S. Schilthuis et al., "Identification of high-risk groups among node-positive patients with stage IB and IIA cervical carcinoma," Gynecologic Oncology, vol. 64, no. 3, pp. 463-467, 1997.

[37] G. Delgado, B. Bundy, R. Zaino, B.-U. Sevin, W. T. Creasman, and F. Major, "Prospective surgical-pathological study of disease-free interval in patients with stage IB squamous cell carcinoma of the cervix: a gynecologic oncology group study," Gynecologic Oncology, vol. 38, no. 3, pp. 352-357, 1990.

[38] A. F. Fuller Jr., N. Elliott, C. Kosloff, W. J. Hoskins, and J. L. Lewis Jr., "Determinants of increased risk for recurrence in patients undergoing radical hysterectomy for Stage IB and IIA carcinoma of the cervix," Gynecologic Oncology, vol. 33, no. 1, pp. 34-39, 1989.

[39] M. Rotman, A. Sedlis, M. R. Piedmonte et al., "A phase III randomized trial of postoperative pelvic irradiation in Stage IB cervical carcinoma with poor prognostic features: follow-up of a gynecologic oncology group study," International Journal of Radiation Oncology Biology Physics, vol. 65, no. 1, pp. 169-176, 2006.

[40] A. Sedlis, B. N. Bundy, M. Z. Rotman, S. S. Lentz, L. I. Muderspach, and R. J. Zaino, "A randomized trial of pelvic radiation therapy versus no further therapy in selected patients with stage IB carcinoma of the cervix after radical hysterectomy and pelvic lymphadenectomy: a gynecologic oncology group study," Gynecologic Oncology, vol. 73, no. 2, pp. 177-183, 1999.

[41] W. A. Peters III, P. Y. Liu, R. J. Barrett II et al., "Concurrent chemotherapy and pelvic radiation therapy compared with pelvic radiation therapy alone as adjuvant therapy after radical surgery in high-risk early-stage cancer of the cervix," Journal of Clinical Oncology, vol. 18, no. 8, pp. 1606-1613, 2000.

[42] J. L. Benedet, F. Odicino, P. Maisonneuve et al., "Carcinoma of the cervix uteri," International Journal of Gynecology and Obstetrics, vol. 83, no. 1, pp. 41-78, 2003.

[43] J. J. Kovalic, C. A. Perez, P. W. Grigsby, and M. A. Lockett, "The effect of volume of disease in patients with carcinoma of the uterine cervix," International Journal of Radiation Oncology Biology Physics, vol. 21, no. 4, pp. 905-910, 1991.

[44] C. W. Whitney, W. Sause, B. N. Bundy et al., "Randomized comparison of fluorouracil plus cisplatin versus hydroxyurea as an adjunct to radiation therapy in stage IIB-IVA carcinoma of the cervix with negative para-aortic lymph nodes: a Gynecologic Oncology Group and Southwest Oncology Group Study," Journal of Clinical Oncology, vol. 17, no. 5, pp. 13391348, 1999.

[45] H. M. Keys, B. N. Bundy, F. B. Stehman et al., "Cisplatin, radiation, and adjuvant hysterectomy compared with radiation and adjuvant hysterectomy for bulky stage IB cervical carcinoma," The New England Journal of Medicine, vol. 340, no. 15, pp. 1154-1161, 1999.

[46] C. Vale, J. F. Tierney, L. A. Stewart et al., "Reducing uncertainties about the effects of chemoradiotherapy for cervical cancer: a systematic review and meta-analysis of individual patient data from 18 randomized trials," Journal of Clinical Oncology, vol. 26, no. 35, pp. 5802-5812, 2008.

[47] S.-K. Lee and H. W. Jones III, "Prognostic significance of ureteral obstruction in primary cervical cancer," International Journal of Gynecology and Obstetrics, vol. 44, no. 1, pp. 59-65, 1994. 
[48] National Cancer Institute Clinical Announcement, "Concurrent Chemoradiation for Cervical Cancer," February 1999, http://www.cancer.gov/newscenter/cervicalcancer.

[49] J. A. Green, J. M. Kirwan, J. F. Tierney et al., "Survival and recurrence after concomitant chemotherapy and radiotherapy for cancer of the uterine cervix: a systematic review and metaanalysis," The Lancet, vol. 358, no. 9284, pp. 781-786, 2001. 


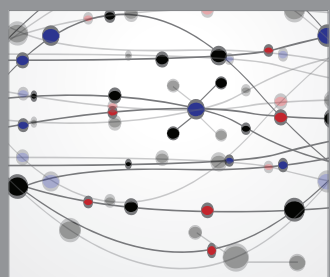

The Scientific World Journal
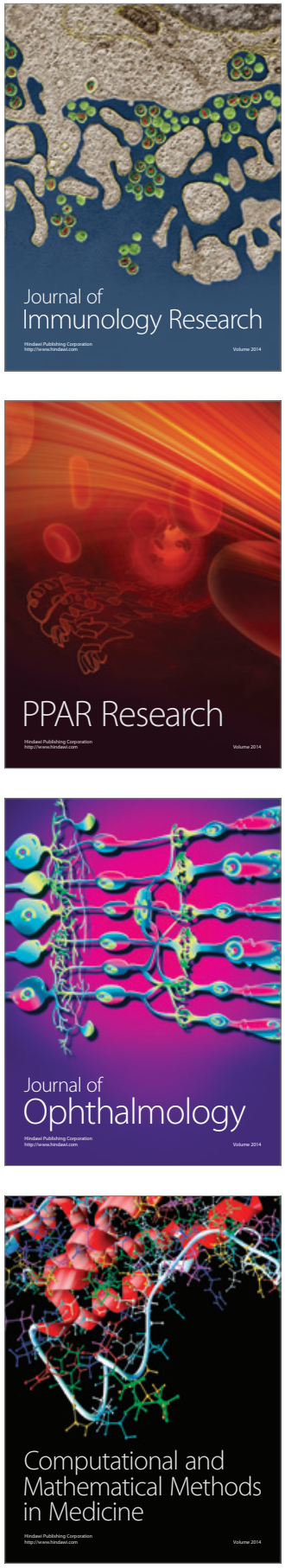

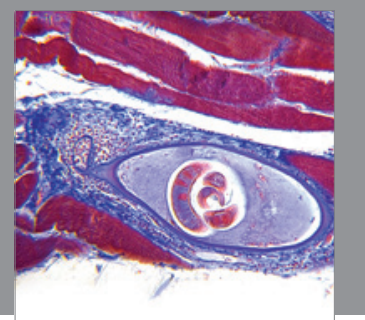

Gastroenterology

Research and Practice
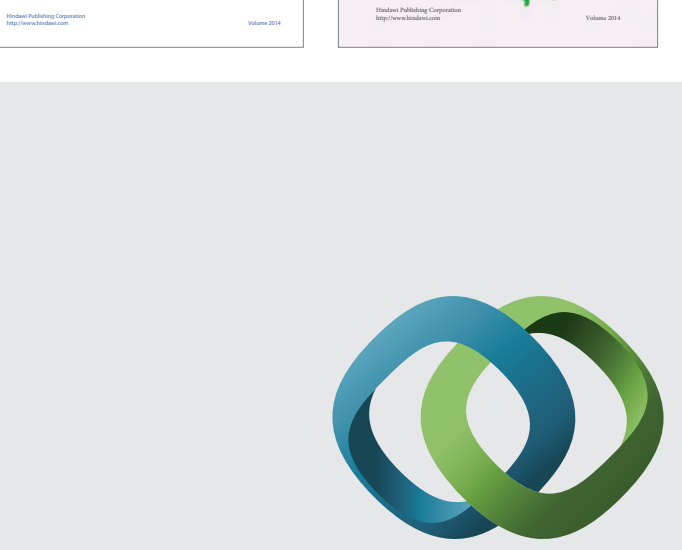

\section{Hindawi}

Submit your manuscripts at

http://www.hindawi.com
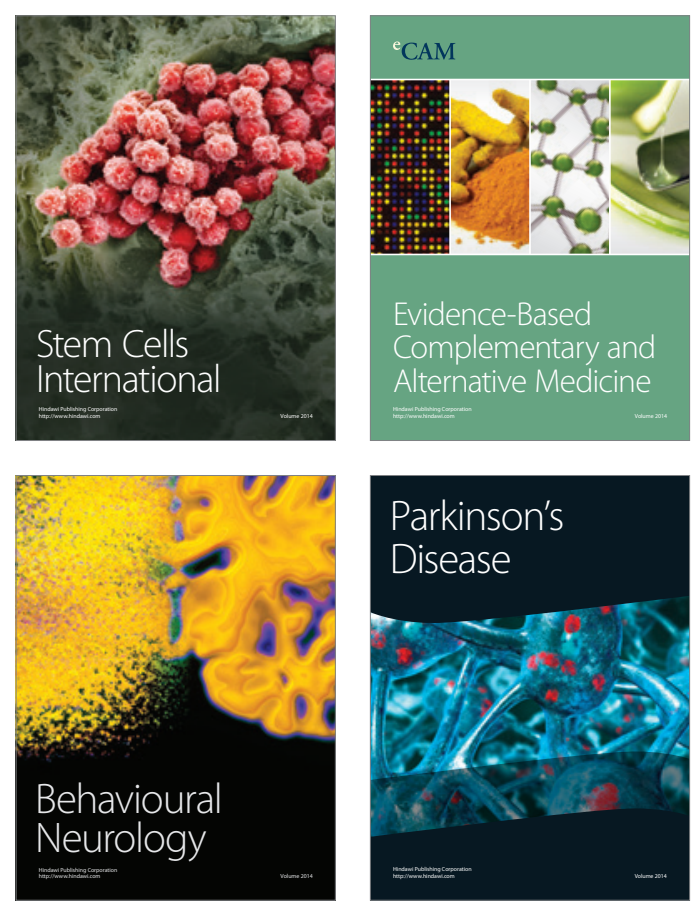

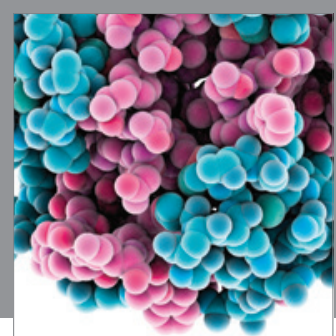

Journal of
Diabetes Research

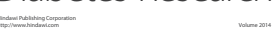

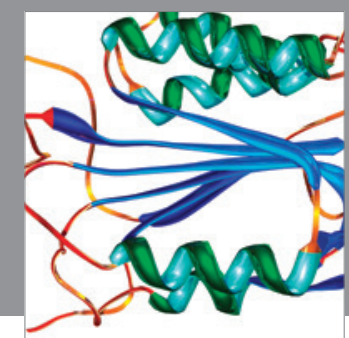

Disease Markers
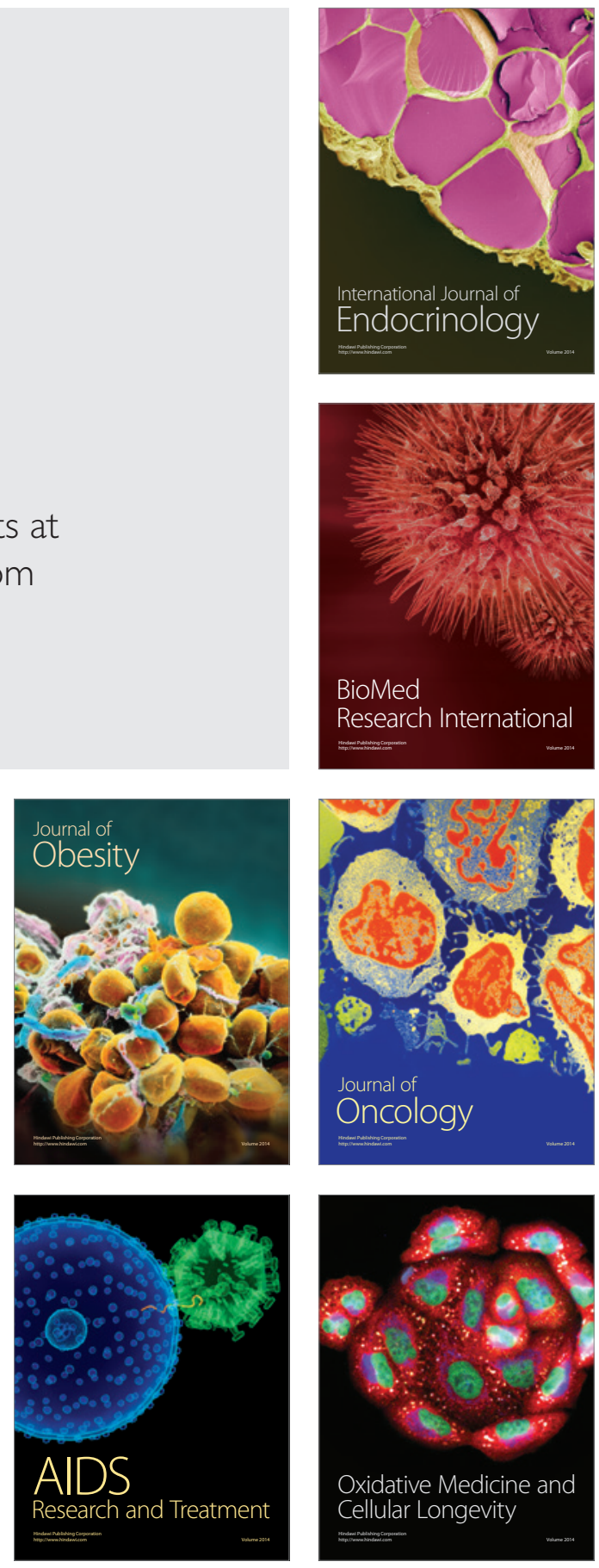